\title{
Effects of Ferric Chloride and Polyaniline Addition on the Properties of Polyethylene Oxide/Polyvinyl Chloride/Polyaniline Conductive Films
}

\author{
Mohammed Izzuddeen Mohd Yazid, ${ }^{1}$ Supri Abdul Ghani, ${ }^{2}$ Azlin Fazlina Osman ${ }^{1 *}$ \\ and Siti Hajar Mohd Din ${ }^{1}$
}

\begin{abstract}
${ }^{1}$ School of Materials Engineering, Universiti Malaysia Perlis (UniMAP), Jejawi-2 School Complex, Taman Muhibbah, 02600 Jejawi, Arau, Perlis, Malaysia

${ }^{2}$ Faculty of Engineering Technology, Universiti Malaysia Perlis (UniMAP),

Level 1, Blok S2, UniCITI Alam Campus, Sungai Chuchuh, Padang Besar, 02100 Perlis, Malaysia
\end{abstract}

*Corresponding author: azlin@unimap.edu.my

Published online: 25 August 2018

To cite this article: Mohd Yazid, M. I. et al. (2018). Effects of ferric chloride and polyaniline addition on the properties of polyethylene oxide/polyvinyl chloride/polyaniline conductive films. J. Phys. Sci., 29(2), 49-63, https://doi.org/10.21315/jps2018.29.2.4

To link to this article: https://doi.org/10.21315/jps2018.29.2.4

\begin{abstract}
Polyethylene oxide (PEO)/polyvinyl chloride (PVC) blends with 2.5$10 \mathrm{wt} \%$ polyaniline (PAni) loadings were fabricated with and without the presence of ferric chloride $\left(\mathrm{FeCl}_{3}\right)$. PEO/PVC/PAni and PEO/PVC/PAni-FeCl $\mathrm{Pl}_{3}$ conductive films were prepared by solution casting method using tetrahydrofuran as the solvent at ambient temperature. The tensile properties, electrical conductivity and structure/morphology of the conductive films were analysed and discussed in this paper. The results indicated that the tensile strength and elongation at break decreased but the Young's modulus increased with PAni loading. Meanwhile, PEO/PVC/PAni-FeCl 3 conductive films showed lower tensile strength and Young's modulus but higher elongation at break in comparison with PEO/ PVC/PAni conductive films. The agglomeration of PAni at higher loadings was revealed by SEM study. However, this study found that higher loading of PAni increased the electrical conductivity of the films and further improved with the addition of $\mathrm{FeCl}_{3}$. The FTIR study revealed the structure of the films with the effect of PAni as filler and $\mathrm{FeCl}_{3}$ as the oxidising agent.
\end{abstract}

Keywords: Polyaniline, ferric chloride, conductive films, mechanical properties, electrical conductivity 


\section{INTRODUCTION}

Polymers are well known typically as insulators as they are generally organic molecules made of carbon, hydrogen and many other elements with covalent bonds. Materials with covalent bond are generally non-conductive due to the absence of free electrons. However, polymer technology is growing rapidly with increasing number of studies on the blending of commercial polymers with conductive polymers being reported in recent years. ${ }^{1-4}$ Polymer blending is a widely preferred approach to establish new polymeric materials. This method is valuable to develop polymers with an extensive range of characteristics such as the blending of conductive polymers with the commercialised, non-conducting polymers.

Intrinsically conductive polymers such as polyaniline (PAni), polypyrole and polytiophene are among the most commonly studied classes of conducting polymers. ${ }^{5}$ PAni has been broadly reviewed for several factors, such as its economic feasibility, environmental stability and the ease of the electronic conductivity to be altered by modifying the oxidation state and degree of doping of the backbone. PAni is a promising material for various techno-commercial applications, and the electrical properties, thermal and environmental stability of PAni film is highly dependent on the nature and the size of its dopant. ${ }^{6}$

Interestingly, PAni can undergo a second cycle of doping process to further improve its electrical conductivity. In 1990, a group of researchers revealed the breakthrough of secondary doping effects in PAni systems. ${ }^{7}$ They reported that the exposure of camphor sulfonic acid-doped PAni to m-cresol improved the electrical conductivity of the sample from $1-2 \mathrm{~S} \mathrm{~cm}^{-1}$ to almost $400 \mathrm{~S} \mathrm{~cm}^{-1}$. Due to the ability of the solvents to efficiently increase the conductivity of PAni, these solvents were generally dubbed as the secondary dopants. ${ }^{8}$ Lately, there has been a plenty of attention given on improving the conductivity of PAni salts by post-polymerisation process with a suitable secondary dopant such as m-cresol solvent. On the other hand, the conductivity of PAni has also been reported to be reliant on the solvent used for casting or solvent they have been exposed to. The solvent generates a modification in the polymer conformation which causes greater electrical conductivity. This phenomenon is also named secondary doping. ${ }^{9}$

It has been reported that the doping process may employ oxidant or also referred to as doping agent to compliment the doping process. Ferric chloride $\left(\mathrm{FeCl}_{3}\right)$, ammonium persulfate, hydrogen persulfate and cerium (IV) sulphate are among the favoured oxidants available. Among them, ferric chloride emerges as one of the most commonly studied oxidants for conducting polymers. $\mathrm{FeCl}_{3}$ became influential after polyacetylene conductivity was found improved with the treatment 
of $\mathrm{FeCl}_{3}$-nitromethane solutions. ${ }^{10}$ Mamma et al. studied the effect on poly $\left(\mathrm{C}_{6} \mathrm{H}_{5} \mathrm{NH}_{2}\right)$ emeraldine salt by $\mathrm{FeCl}_{3}$ and $\mathrm{KMnO}_{4}$ as secondary dopants and found out that the conductivity has dramatically increased. The secondary doping causes structural rearrangement of PAni, from a compact-coil form to a more expandable conformation. In addition, it is also reported that the $\pi$ conjugation increased due to the secondary doping. ${ }^{8}$

In this paper, polyethylene oxide (PEO) and polyvinyl chloride (PVC) were selected as the matrix materials and were blended with the PAni filler to produce PEO/ PVC/PAni conductive films. PVC has been widely exploited in polymer industry and attracting many researchers to explore various potentials of the polymer. PVC offers many benefits such as low in cost, good processability and also compatible with numerous plasticisers. It has been widely used as construction pipes, flooring materials and cable sheathes. However, the number of research works involving the investigation of PVC for more advance field such as in electronic application is rising from year to year. For several decades, various approaches have been developed to improve electrical conductivity of PVC. ${ }^{11,12}$ It includes blending PVC with conductive polymer, coating PVC surfaces with conductive layers, mixing the PVC with liquid anti-static agents, and even by adding conductive inorganic fillers into the PVC. ${ }^{13}$

PEO is a polymer of great interest which offers superior solvating ability for salt while establishing better stability with inorganic salts. ${ }^{14}$ Moreover, PEO shows sufficient thermal and chemical stability, and the spacing between the ether groups along the PEO backbone is ideal for cation solvation. Papers on PEO/PVC blend have been widely reported by fellow scholars. The vital point to keep in mind when constructing new polymer blends is the miscibility of a blend. ${ }^{15,16}$ Ramesh and Arof investigated the PVC/PEO miscibility at various ratio and concluded that the blends were miscible. ${ }^{17}$ In addition, Silva et al. also reported similar finding after concluding that $\mathrm{PVC} / \mathrm{PEO}$ blends were miscible in their study. ${ }^{18}$

In this study, we have analysed the effect of $\mathrm{FeCl}_{3}$ addition and PAni loading on the $\mathrm{PEO} / \mathrm{PVC} / \mathrm{PAni}$ conductive films where the PAni used was already prepared in emeraldine salt form. Although a significant number of papers have discussed the effect of doping on PAni, there are still limited works reported on doping PAni in emeraldine salt form. Besides, the method of using oxidants, $\mathrm{FeCl}_{3}$, without using any type of acidic solvent can be considered as a novelty in this field of research. The main objective of the work was to study the tensile properties, electrical conductivity, morphology and chemical structure of the films with and without the presence of $\mathrm{FeCl}_{3}$. The effects of PAni loading on the structure and properties of the conductive films were also reported. 


\section{EXPERIMENTAL}

\subsection{Materials}

PEO powder with molecular weight of $100,000 \mathrm{~g} \mathrm{~mol}^{-1}$ was used in this study. It has glass transition temperature of $-53^{\circ} \mathrm{C}$ to $-45^{\circ} \mathrm{C}$ and melting temperature of $65^{\circ} \mathrm{C}$. PVC powder had the molecular weight of $220,000 \mathrm{~g} \mathrm{~mol}^{-1}$, glass transition temperature of $84^{\circ} \mathrm{C}$ and melting temperature of $100^{\circ} \mathrm{C}$ to $160^{\circ} \mathrm{C}$. Both $\mathrm{PEO}$ and PVC were provided by AR Alatan Sdn. Bhd., Alor Star, Malaysia. PAni (emeraldine salt with $20 \mathrm{wt} \%$ of carbon black) with particle size of $21 \mu \mathrm{m}$ and approximated molecular weight of 5000 was manufactured by Sigma Aldrich. Ferric chloride, $\mathrm{FeCl}_{3}$, with molar mass of $162.2 \mathrm{~g} \mathrm{~mol}^{-1}$ and density of $2.9 \mathrm{~g} \mathrm{~cm}^{-3}$ was supplied by AR Alatan Sdn. Bhd. Tetrahydrofuran with molecular weight of $72.11 \mathrm{~g} \mathrm{~mol}^{-1}$ and dioctyl terephthalate (DOTP) with molecular weight of $390 \mathrm{~g} \mathrm{~mol}^{-1}$ were used in this research. Finally, ethanol $\left(\mathrm{C}_{2} \mathrm{H}_{5} \mathrm{OH}\right)$ with molar mass of $46.07 \mathrm{~g} \mathrm{~mol}^{-1}$ and density of $0.79 \mathrm{~g} \mathrm{~cm}^{-3}$ was supplied also by AR Alatan Sdn. Bhd.

\subsection{Conductive Films Preparation}

The sample fabrication was carried out by solution casting method. Both the PEO powder and PVC powder were dissolved in a separate conical flask with THF solvent. After that, the PEO and PVC solution were mixed in a single conical flask before it was then stirred to become homogeneous. Next, DOTP and PAni were added into the homogeneous solution. To accomplish a suitable viscosity and decent homogeneous condition, the solution was stirred via magnetic stirrer at $400 \mathrm{rpm}$ for $4 \mathrm{~h}$. Lastly, the solution was casted onto a glass mold and left until it dried slowly inside a fume cupboard. Table 1 displays the formulation employed in this research.

Table 1: Formulations of $\mathrm{PEO} / \mathrm{PVC} / \mathrm{PAni}$ conductive films and $\mathrm{PEO} / \mathrm{PVC} / \mathrm{PAni}-\mathrm{FeCl}_{3}$ conductive films with different polyaniline loading.

\begin{tabular}{lccc}
\hline Conductive films code & PEO/PVC (40:60) $(\mathrm{wt} \%)$ & DOTP $(\mathrm{wt} \%)$ & PAni (wt $\%)$ \\
\hline PEO/PVC & 85 & 15 & - \\
PEO/PVC /PAni-2.5 & 82.5 & 15 & 2.5 \\
PEO/PVC /PAni-5 & 80 & 15 & 5 \\
PEO/PVC /PAni-7.5 & 77.5 & 15 & 7.5 \\
PEO/PVC /PAni-10 & 75 & 15 & 10 \\
PEO/PVC /PAni-FeCl ${ }_{3}-2.5$ & 82.5 & 15 & 2.5 \\
PEO/PVC /PAni-FeCl -5 & 80 & 15 & 5 \\
PEO/PVC /PAni-FeCl -7.5 & 77.5 & 15 & 7.5 \\
PEO/PVC /PAni-FeCl -10 & 75 & 15 & 10 \\
\hline
\end{tabular}




\subsection{Preparation of Secondary Doping of Polyaniline with $\mathrm{FeCl}_{3}$}

PAni were dissolved with $6 \mathrm{wt} \%$ of ferric chloride in toluene and then stirred for $24 \mathrm{~h}$. Next, the doped mixture was washed with distilled water and dried in an oven for $5 \mathrm{~h}$ at $60^{\circ} \mathrm{C}$. Finally, the doped PAni powders were grinded to fine powders and ready to preserve for sample preparations.

\subsection{Tensile Test}

The tensile properties of the samples were assessed by using Universal Testing Machine Instron 5569 according to ASTM D638. Rectangular shaped specimens were tested at relative humidity $30^{\circ} \mathrm{C} \pm 2^{\circ} \mathrm{C}$ and ambient temperature $25^{\circ} \mathrm{C} \pm 3^{\circ} \mathrm{C}$ with the crosshead speed of $30 \mathrm{~mm} \mathrm{~min}^{-1}$. The tensile strength and Young's modulus data were acquired from the average values of five samples for each sample.

\subsection{SEM}

The morphology of the conductive films was analysed via JEOL JSM-6460LA. The films were cut into square shaped sample to fit the dimension of the SEM aluminium stubs. Prior to viewing, the samples were sputter-coated with a thin palladium layer of $20 \mathrm{~nm}$ to prevent electrostatic charges during analysis.

\subsection{Electrical Conductivity Test}

The conductivity of the conductive film was analysed via Keithley Model 4200SCS semiconductor characterisation system. Each sample's conductivity was carried out with four-point probe with voltage varied from $0 \mathrm{~V}$ to $10 \mathrm{~V}$. The value of conductivity was calculated using its correlation with resistivity. With the probes centred on a very wide and very thin sample, the conductivity can be calculated via Equations 1 and 2:

$$
\rho=\left(\frac{\pi}{\ln 2}\right) t\left(\frac{V}{I}\right)
$$

where $\rho=$ resistivity, $t=$ sample thickness, $V=$ voltage between two inner probes, $I=$ current flows between two outer probes and the conductivity, $\sigma$, was calculated using the Equation 2:

$$
\sigma=\frac{1}{\rho}
$$




\subsection{FTIR Spectroscopy}

The Fourier Transform Infrared (FTIR) spectra of the thin conductive film were obtained by using Perkin-Elmer Spectrum 400 Series equipment. Attenuated total reflectance (ATR) technique was applied with preferred spectrum resolution of $4 \mathrm{~cm}^{-1}$. The 16 scans in scanning range of $650 \mathrm{~cm}^{-1}$ to $4000 \mathrm{~cm}^{-1}$ were recorded. Lastly, the FTIR spectra with percentage transmittance versus wavelength $\left(\mathrm{cm}^{-1}\right)$ were attained after scanning process.

\section{RESULTS AND DISCUSSION}

\subsection{Tensile Properties}

The tensile strength of $\mathrm{PEO} / \mathrm{PVC} / \mathrm{PAni}$ and $\mathrm{PEO} / \mathrm{PVC} / \mathrm{PAni}-\mathrm{FeCl}_{3}$ conductive films were studied and plotted as a function of PAni loading and $\mathrm{FeCl}_{3}$ effect (shown in Figure 1). It can be observed that the tensile strength decreased gradually with the increasing loading of PAni. This can be explained by the weak filler-matrix interaction besides the unsatisfactory dispersion of PAni in the films. The same finding was reported by other researchers who claimed that PAni established globular aggregates in matrix, which as a result, weakened the tensile strength. ${ }^{19,20}$ Figure 1 also represents the effect of $\mathrm{FeCl}_{3}$ on the tensile strength of the films. It can be observed that $\mathrm{PEO} / \mathrm{PVC} / \mathrm{PAni}$ conductive films have higher tensile strength than $\mathrm{PEO} / \mathrm{PVC} / \mathrm{PAni}-\mathrm{FeCl}_{3}$ conductive films. The same behaviour has been stated by Marins and his fellow researchers as they found out that the PAni reacted with $\mathrm{FeCl}_{3}$ for 180 min and subsequently decreased the tensile strength. ${ }^{21}$ This showed that in a longer period of time, $\mathrm{FeCl}_{3}$ gave negative effect on the tensile strength of the films. They reported that the electrical conductivity of the PAni membrane showed an increasing trend from $15 \mathrm{~min}$ to $180 \mathrm{~min}$ and might further increase if more time is applied. In another report, Zhang et al. stated that $24 \mathrm{~h}$ were the required time to complete the polymerisation of aniline and $\mathrm{FeCl}_{3}$ due to the lower oxidation/reduction potential of $\mathrm{FeCl}_{3}$ as the oxidant. ${ }^{22}$

Figure 2 shows the influence of PAni loading on the Young's modulus of PEO/PVC/ PAni and $\mathrm{PEO} / \mathrm{PVC} / \mathrm{PAni}-\mathrm{FeCl}_{3}$ conductive films. The Young's modulus for both films increased with increasing PAni loading signalling that PAni delivered greater stiffness to the conductive films with more PAni loading addition. Moreover, PAni is also acknowledged as a very rigid material. ${ }^{23}$ It reduced the flexibility of $\mathrm{PEO} /$ PVC chain, thus injecting higher stiffness to the films. In a similar report by Nand and his fellow researchers, Young's modulus of linear low-density polyethylene (LLDPE)/nanorod-polyaniline (NR-PAni) blend increased with the addition of the filler, NR-PAni. It is understood that the rigidity of the blend increased as 
filler particles filled in the spaces in the matrix, therefore increasing its Young's modulus. ${ }^{24}$ At similar composition, the introduction of $\mathrm{FeCl}_{3}$ in $\mathrm{PEO} / \mathrm{PVC} / \mathrm{PAni}$ $\mathrm{FeCl}_{3}$ conductive films was demonstrated in Figure 2. The Young's modulus of the films decreased with the addition of the oxidant, $\mathrm{FeCl}_{3}$. This trend is in line with a report from Thanpitcha et al. in which the modulus of doped PAni/chitosan blend films was lower than the PAni/chitosan before the doping process. ${ }^{25}$ They explained that PAni is more crystalline at greater doping levels, thus decreasing the Young's modulus of the films.

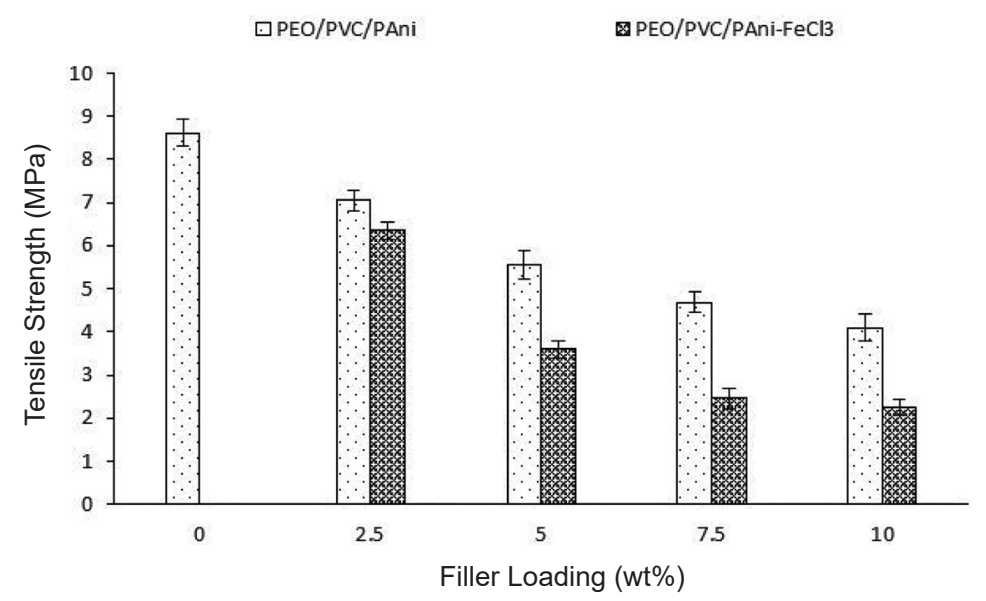

Figure 1: Tensile strength vs. filler loading of PEO/PVC/PAni conductive films and PEO/ $\mathrm{PVC} / \mathrm{PAni}-\mathrm{FeCl}_{3}$ conductive films.

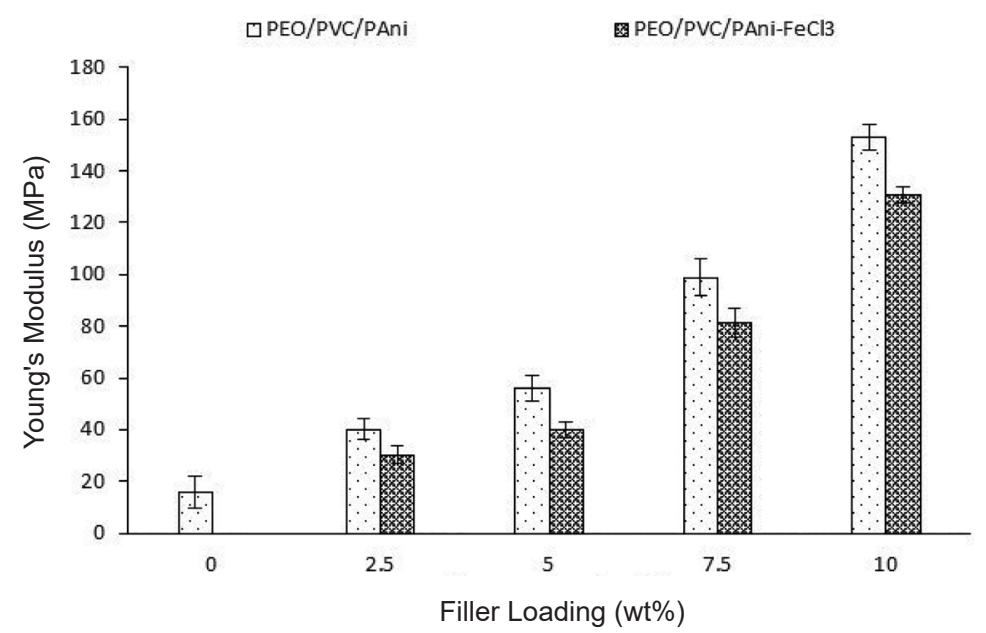

Figure 2: Young's modulus vs. filler loading of PEO/PVC/PAni conductive films and $\mathrm{PEO} / \mathrm{PVC} / \mathrm{PAni}-\mathrm{FeCl}_{3}$ conductive films. 
The effect of filler loading on elongation at break is shown in Figure 3. According to Ghani et al., the elongation at break of the composites mainly depends on the filler content. ${ }^{26}$ In their study on LDPE/chicken feather fibre (CFF) composites, they found that the filler has hardened the composites and reduced their ductility. Therefore, the elongation at break decreased upon fillers addition where the fillers were responsible for the decrement of the composite toughness. In contradiction, a higher value of elongation at break of $\mathrm{PEO} / \mathrm{PVC} / \mathrm{PAni}-\mathrm{FeCl}_{3}$ conductive films compared to $\mathrm{PEO} / \mathrm{PVC} / \mathrm{PAni}$ conductive films at the same filler loading can be observed in Figure 3. This higher elongation at break occurred due to the plasticisation effect of $\mathrm{FeCl}_{3}$ in $\mathrm{PVC}$ as confirmed by Mano et al. ${ }^{27}$ The plasticisation effect of $\mathrm{FeCl}_{3}$ was explained by the ion pair established between $\mathrm{FeCl}_{3}$ and $\mathrm{PVC}$ which generated more flexible segments in the chain.

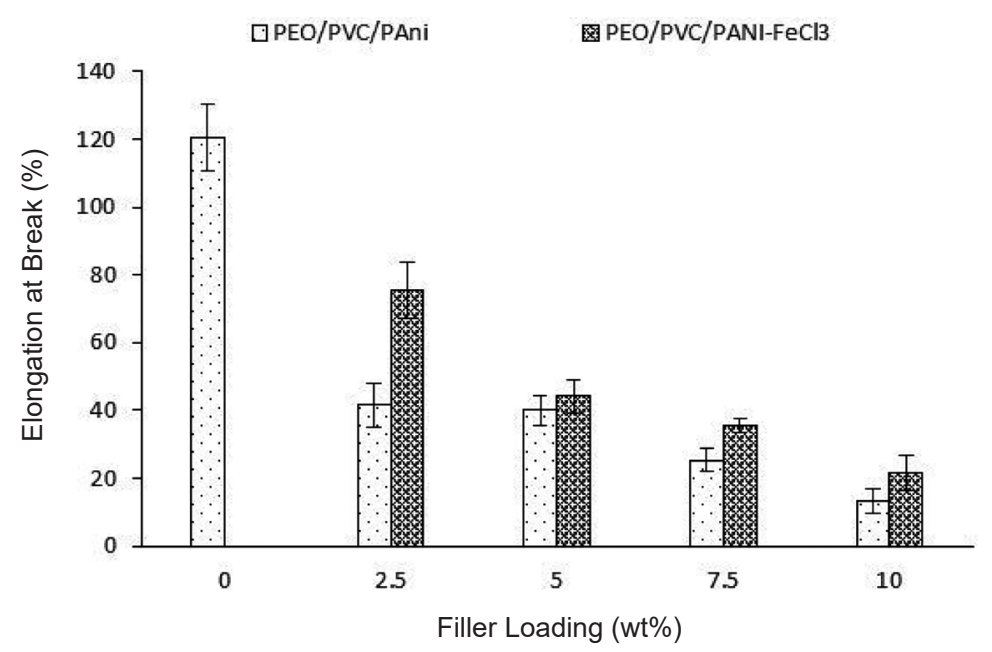

Figure 3: Elongation at break vs. filler loading of PEO/PVC/PAni conductive films and $\mathrm{PEO} / \mathrm{PVC} / \mathrm{PAni}-\mathrm{FeCl}_{3}$ conductive films.

\subsection{Morphology Analysis}

The SEM morphologies of PEO/PVC films, PEO/PVC/PAni conductive films and $\mathrm{PEO} / \mathrm{PVC} / \mathrm{PAni}-\mathrm{FeCl}_{3}$ conductive films are represented in Figure 4. The analysis was carried out to visualise the effect of PAni loading and $\mathrm{FeCl}_{3}$ addition on the mechanical properties of the films. Figure 4(a) of PEO/PVC blend shows a smooth surface morphology, signalling the miscibility of PEO and PVC blends. The morphologies of PEO/PVC/PAni conductive films were displayed in Figures 4(b) and $4(\mathrm{c})$ whereas the micrographs of $\mathrm{PEO} / \mathrm{PVC} / \mathrm{PAni}-\mathrm{FeCl}_{3}$ conductive films were demonstrated in Figures 4(d) and 4(e). In can be seen from Figures 4(b) and 4(d) that both films at $5 \mathrm{wt} \%$ PAni loading showed better dispersion of fillers and less 
voids compared with Figures 4(c) and 4(e) of $10 \mathrm{wt} \%$ PAni loading. This suggests that higher amount of filler have a tendency to form agglomeration which causes mediocre stress transfer across the interfaces. This in turn will lead to weaker tensile strength at higher PAni loading, as supported by the tensile strength result.

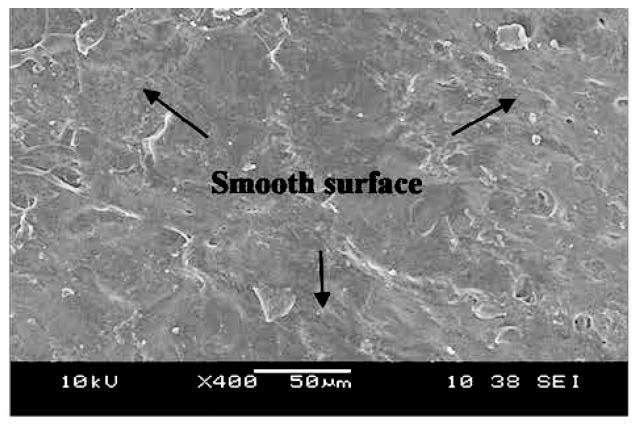

(a) $\mathrm{PEO} / \mathrm{PVC}$

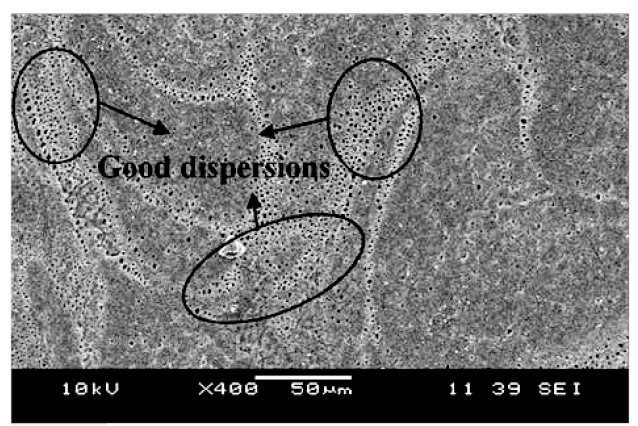

(b) $\mathrm{PEO} / \mathrm{PVC} / \mathrm{PAni}-5$

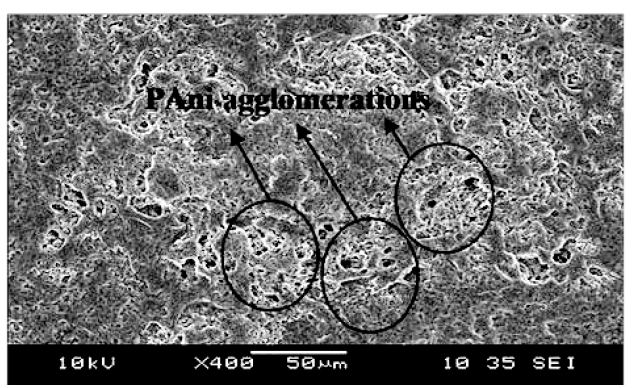

(c) $\mathrm{PEO} / \mathrm{PVC} / \mathrm{PAni} \mathrm{FeCl}_{3}-5$

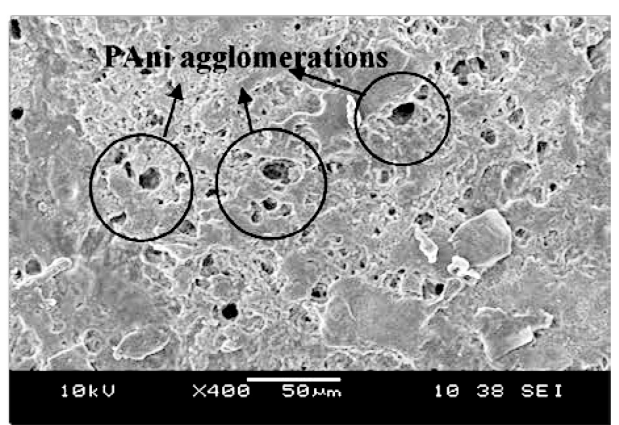

(c) $\mathrm{PEO} / \mathrm{PVC} / \mathrm{PAni}-10$

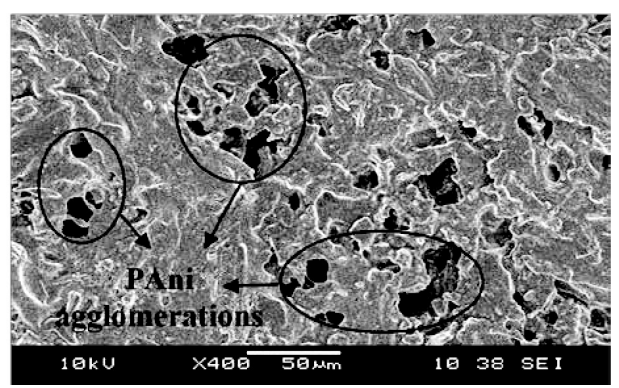

(f) $\mathrm{PEO} / \mathrm{PVC} / \mathrm{PAni} \mathrm{FeCl}_{3}-10$

Figure 4: SEM morphology of extracted surface of PEO/PVC, PEO/PVC/PAni and PEO/ $\mathrm{PVC} / \mathrm{PAni}-\mathrm{FeCl}_{3}$ conductive films at different filler loadings. 
The effect of $\mathrm{FeCl}_{3}$ inclusion on the morphology of the PEO/PVC/PAni- $\mathrm{FeCl}_{3}$ conductive films are shown in Figures 4(d) and 4(e). PEO/PVC/PAni-FeCl ${ }_{3}-5$ conductive films and $\mathrm{PEO} / \mathrm{PVC} / \mathrm{PAni}-\mathrm{FeCl}_{3}-10$ conductive films exhibited poorer surface morphology in comparison with the other conductive films without the presence of $\mathrm{FeCl}_{3}$. Additionally, the SEM micrograph from Figures 4(d) and 4(e) displayed poor dispersion and agglomeration of the fillers as a result of $\mathrm{FeCl}_{3}$ ion $\left(\mathrm{Fe}^{3+}+3 \mathrm{Cl}^{-}\right)$reducing the PEO/PVC miscibility and weakening the interaction. These results match with the finding of the tensile strength results where $\mathrm{PEO} /$ $\mathrm{PVC} / \mathrm{PAni}-\mathrm{FeCl}_{3}$ conductive films had lower tensile strength than $\mathrm{PEO} / \mathrm{PVC} / \mathrm{PAni}$ conductive films.

\subsection{Electrical Conductivity}

Figure 5 illustrates the electrical conductivity of $\mathrm{PEO} / \mathrm{PVC} / \mathrm{PAni}$ and $\mathrm{PEO} / \mathrm{PVC} /$ PAni- $\mathrm{FeCl}_{3}$ conductive films. The graph indicates that the conductivity of the films increased with increasing of PAni loading. This could be due to the addition of PAni emeraldine salt form which contains highly $\pi$ conjugated backbone. ${ }^{25}$ Electrons were delocalised along the conjugated backbones of PAni, which subsequently developed free movement of electrons from atom to atom and generating electrical charge.

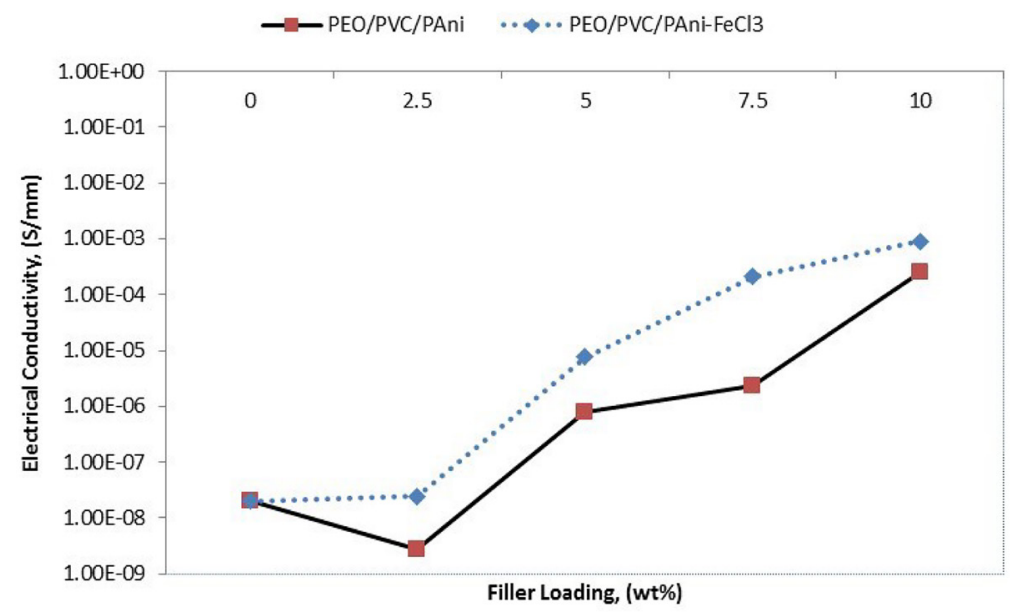

Figure 5: Electrical conductivity of $\mathrm{PEO} / \mathrm{PVC} / \mathrm{PAni}$ conductive films and $\mathrm{PEO} / \mathrm{PVC} /$ PAni- $\mathrm{FeCl}_{3}$ conductive films at different filler loadings.

Meanwhile, $\mathrm{PEO} / \mathrm{PVC} / \mathrm{PAni}-\mathrm{FeCl}_{3}$ conductive films demonstrated improved electrical conductivity compared with $\mathrm{PEO} / \mathrm{PVC} / \mathrm{PAni}$ conductive films. The result is supported by $\mathrm{Li}$ et al. in which they reported that the conductivity of the synthesided PAni- $\mathrm{FeCl}_{3}$ was higher than the single PAni. ${ }^{28}$ In addition, there 
were several reports proposing that $\mathrm{FeCl}_{3}$ can perform as dopant and oxidant at the same time as $\mathrm{FeCl}_{3}$, being an acidic salt, offers protons in aqueous solution by hydrolysis. ${ }^{28-30}$ No acidic solvent (dopant) was used in this research to dope the PAni. The ability of the oxidant $\left(\mathrm{FeCl}_{3}\right)$ to perform as dopant has been utilised and it resulted in higher electrical conductivity compared to the films without $\mathrm{FeCl}_{3}$ as displayed in Figure 5. The mechanism of $\mathrm{PAni}_{-} \mathrm{FeCl}_{3}$ re-doping reaction has been proposed in Figure 6. As displayed in Figure 6, the re-doping process enhanced the deformed structure of PAni as a result of $\mathrm{FeCl}_{3}$ ion substitute in $\mathrm{PEO} / \mathrm{PVC} /$ PAni- $\mathrm{FeCl}_{3}$ conductive films. Moreover, the free electron from $\mathrm{FeCl}_{3}-\mathrm{NH}$ of the PAni backbone would increase the free electron movement in the conductive films. Released free electrons resulted in movement of electron from atom to atom which increased the electrical conductivity.

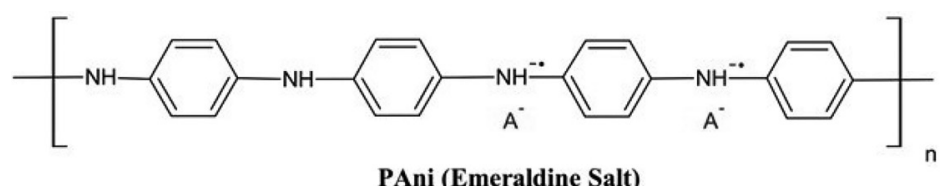

PAni (Emeraldine Salt)

$\downarrow \begin{aligned} & \text { Room temperature } \\ & \text { Mixing PAni and } \mathrm{FeCl}_{3} \text { for } 24 \text { hours } \\ & \text { Dissolve in ethanol (EtOH) }\end{aligned}$

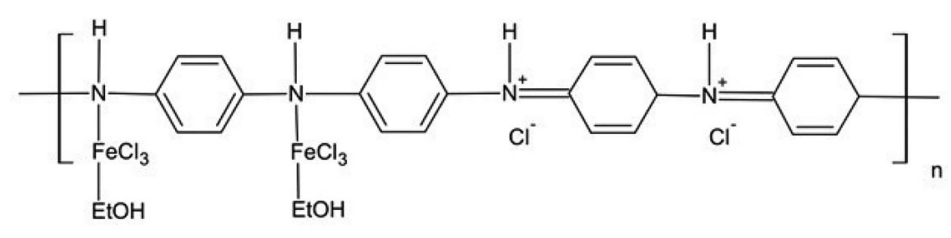

PAni (Emeraldine Salt) redoped with $\mathrm{FeCl}_{3}$ in ethanol

Figure 6: The proposed mechanism of $\mathrm{PAni}-\mathrm{FeCl} 3$ redoping reaction.

\subsection{Spectroscopy Infrared Analysis}

The FTIR spectra of the PEO/PVC/PAni conductive films and PEO/PVC/PAni$\mathrm{FeCl}_{3}$ conductive films are presented in Figure 7. From the spectra, the absorption of $2885.91 \mathrm{~cm}^{-1}$ and $2887.67 \mathrm{~cm}^{-1}$ indicated $\mathrm{CH}_{2}$ asymmetric stretching attributed to PEO and PVC structure. It can be observed that the band at $1715.79 \mathrm{~cm}^{-1}$ and $1717.04 \mathrm{~cm}^{-1}$ corresponded to $\mathrm{C}=\mathrm{O}$ stretching of $\mathrm{PEO}$, whereas the peaks at $1465.95 \mathrm{~cm}^{-1}$ and $1466.98 \mathrm{~cm}^{-1}$ attributed to $\mathrm{CH}_{2}$ deformation. Moreover, the peak at $1342.38 \mathrm{~cm}^{-1}$ from PEO/PVC/PAni- $\mathrm{FeCl}_{3}$ conductive films can be assigned with the $\mathrm{CH}_{2}$ vibration. The absorption at $1274.90 \mathrm{~cm}^{-1}$ and $1278.84 \mathrm{~cm}^{-1}$ were 
identified, which are ascribed to the strong vibration of $\mathrm{C}-\mathrm{O}$ structure. The peaks of C-O-C and C-O groups were also spotted at the peak range of $1000 \mathrm{~cm}^{-1}$ to $1150 \mathrm{~cm}^{-1}$. Lastly, the intensity peaks at $962.95 \mathrm{~cm}^{-1}, 960.96 \mathrm{~cm}^{-1}, 843.16 \mathrm{~cm}^{-1}$ and $841.97 \mathrm{~cm}^{-1}$ exhibited the characteristics peaks of gauche conformation of [- $\left.\mathrm{CH}_{2}-\mathrm{CH}_{2}-\right]$ group for pure PEO. In short, the presence of $\mathrm{FeCl}_{3}$ did not create new functional group in the conductive films.

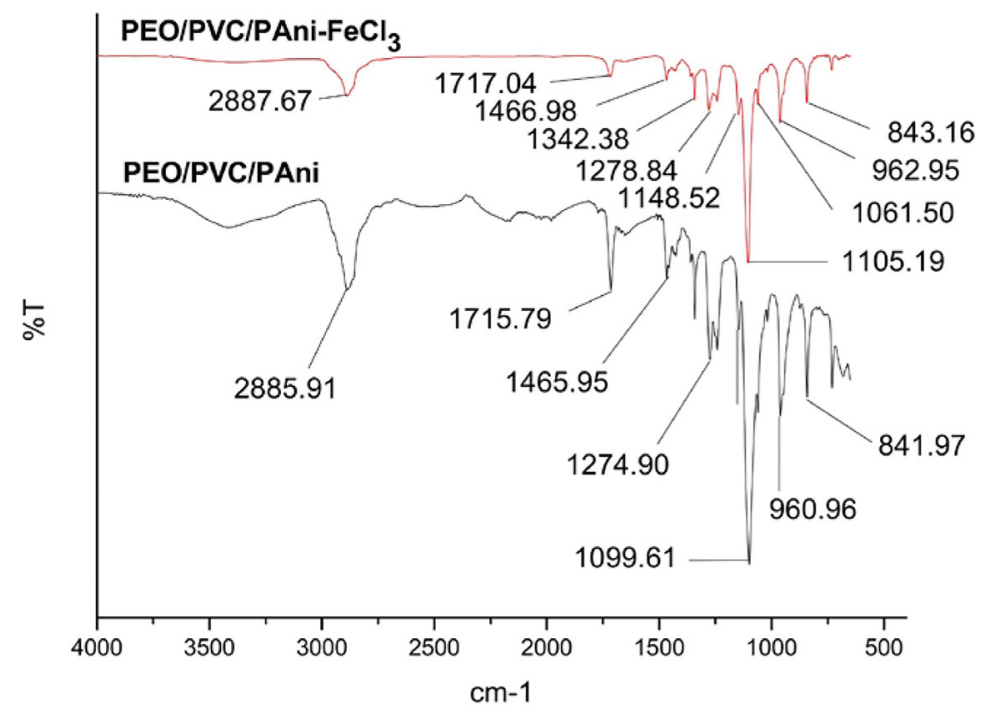

Figure 7: FTIR spectra of PEO/PVC/PAni conductive films and PEO/PVC/PAni-FeCl $\mathrm{Pl}_{3}$ conductive films.

\section{CONCLUSION}

$\mathrm{PEO} / \mathrm{PVC} / \mathrm{PAni}$ and $\mathrm{PEO} / \mathrm{PVC} / \mathrm{PAni}-\mathrm{FeCl}_{3}$ conductive films were prepared by solution casting technique. It was observed that the tensile strength and elongation at break of the films were reduced with the addition of PAni. However, the Young's modulus values were found to be increased with the addition of PAni. At similar loading, the presence of $\mathrm{FeCl}_{3}$ downgraded the tensile strength and the Young's modulus of the films but improved the elongation at break. The SEM morphology of $\mathrm{PEO} / \mathrm{PVC} / \mathrm{PAni}$ and $\mathrm{PEO} / \mathrm{PVC} / \mathrm{PAni}-\mathrm{FeCl}_{3}$ conductive films supported the tensile results by showing more voids and agglomeration as more PAni loading incorporated as well as when the $\mathrm{FeCl}_{3}$ were introduced into the films. On the other hand, the electrical conductivity of the films was found to increase with higher loading of PAni and further improved with the introduction of $\mathrm{FeCl}_{3}$. Finally, the FTIR spectra indicated that no new functional group formed between the films and $\mathrm{FeCl}_{3}$. 


\section{REFERENCES}

1. Devendrappa, H., Rao, U. S. \& Prasad, M. A. (2006). Study of DC conductivity and battery application of polyethylene oxide/polyaniline and its composites. J. Power Sourc., 155, 368-374, https://doi.org/10.1016/j. jpowsour.2005.05.014.

2. Subrahmanyam, A. R. et al. (2012). Mechanical and electrical conductivity studies of PANI-PVA and PANI-PEO blends. Int. J. Mater. Sci., 2, 27-30.

3. Tang, L. C. et al. (2013). The effect of graphene dispersion on the mechanical properties of graphene/epoxy composites. Carbon, 60, 16-27, https://doi. org/10.1016/j.carbon.2013.03.050

4. Das, T. K. \& Prusty, S. (2013). Graphene-based polymer composites and their applications. Polym-Plast. Technol., 52, 319-331.

5. Rimbu, G. A. et al. (2006). The morphology control of polyaniline as conducting polymer in fuel cell technology. J. Optoelectr. Adv. M, 8, 670-674.

6. Chauhan, N. P. et al. (2011). Thermal and conducting behaviour of emeraldine base (EB) form of polyaniline (PANI). Ind. J. Chem. Tech., 18, 118-122.

7. Wei, Y. et al. (1990). Polymerization of aniline and alkyl ring-substituted anilines in the presence of aromatic additives. J. Phys. Chem., 94, 77167721. https://doi.org/10.1021/j100382a073.

8. Mamma, K., Siraj, K. \& Meka, N. (2013). Effect on poly $\left(\mathrm{C}_{6} \mathrm{H}_{5} \mathrm{NH}_{2}\right)$ emeraldine salt by $\mathrm{FeCl} 3$ and $\mathrm{KMnO} 4$ as secondary dopants. Am. J. Polym. Sci. Eng., 1, 1-13.

9. MacDiarmid, A. G. \& Epstein, A. J. (1995). Secondary doping in polyaniline. Synth. Met., 69, 85-92, https://doi.org/10.1016/0379-6779(94)02374-8.

10. Genoud, F. et al. (2000). Lewis acid doped polyaniline. Part II: Spectroscopic studies of emeraldine base and emeraldine hydrochloride complexation with $\mathrm{FeCl}_{3}$. Chem. Mater., 12(3), 744-749, https://doi.org/10.1021/cm990485u.

11. Saad, A. L. G., Aziz, H. A. \& Dimitry, O. I. H. (2004). Studies of electrical and mechanical properties of poly (vinyl chloride) mixed with electrically conductive additives. J. Appl. Polym. Sci., 91, 1590-1598, https://doi. org/10.1002/app.13239.

12. Vadukumpully, S. et al. (2011). Flexible conductive graphene/poly (vinyl chloride) composite thin films with high mechanical strength and thermal stability. Carbon, 49, 198-205, https://doi.org/10.1016/j.carbon.2010.09.004.

13. Wang, H. et al. (2015). Electrical and mechanical properties of antistatic PVC films containing multi-layer graphene. Compos. B, 79, 444-450.

14. Karmakar, A. \& Ghosh, A. (2012). Dielectric permittivity and electric modulus of polyethylene oxide (PEO)-LiClO 4 composite electrolytes. Curr. Appl. Phys., 12, 539-543, https://doi.org/10.1016/j.cap.2011.08.017. 
15. da Silva Neiro, S. M. et al. (2000). Miscibility of PVC/PEO blends by viscosimetric, microscopic and thermal analyses. Eur. Polym. J., 36, 583589, https://doi.org/10.1016/S0014-3057(99)00082-8.

16. MacCallum, J. R. \& Smith, J. S. G. (2000). A novel method for producing miscible polymer blends. Eur. Polym. J., 36, 491-494, https://doi.org/ 10.1016/S0014-3057(99)00110-X

17. Ramesh, S. \& Arof, A. K. (2009). The evaluation of miscibility of poly (vinyl chloride) and poly (ethylene oxide) blends by DSC, refractive index and XRD analyses. Int. Polym. Proc., 24, 354-358, https://doi.org/10.3139/217.2275.

18. Silva, E. P., Kaplan, M. A. C. \& Tavares, M. I. B. (2007). ${ }^{13}$ C solid state NMR study of the PVC/PEO/Gypsum system. Ann. Magn. Res., 6, 83-87.

19. Jeevananda, T. (2003). Synthesis and characterization of polyaniline filled PU/PMMA interpenetrating polymer networks. Eur. Polym. J., 39, 569-578, https://doi.org/10.1016/S0014-3057(02)00272-0.

20. Soares, B. G. \& Leyva, M. E. (2007). Effect of blend preparation on electrical, dielectric, and dynamical-mechanical properties of conducting polymer blend: SBS triblock copolymer/polyaniline. Macromol. Mater. Eng., 292, 354-361, https://doi.org/10.1002/mame.200600405.

21. Marins, J. A. et al. (2014). Self-supported bacterial cellulose polyaniline conducting membrane as electromagnetic interference shielding material: Effect of the oxidizing agent. Cell., 21, 1409-1418.

22. Zhang, L., Wan, M. \& Wei, Y. (2006). Nanoscaled polyaniline fibers prepared by ferric chloride as an oxidant. Macromol. Rapid Comm., 27, 366-371, https://doi.org/10.1002/marc.200500760.

23. Bhadra, J. et al. (2015). Effects of aniline concentrations on the electrical and mechanical properties of polyaniline polyvinyl alcohol blends. Arab. J. Chem., 10, 664-672, https://doi.org/10.1016/j.arabjc.2015.04.017.

24. Nand, A. V. et al. (2012). Characterization of antioxidant low density polyethylene/polyaniline blends prepared via extrusion. Mater. Chem. Phys., 135, 903-911, https://doi.org/10.1016/j.matchemphys.2012.05.077.

25. Thanpitcha, T. et al. (2006). Preparation and characterization of polyaniline/ chitosan blend film. Carbohydr. Polym., 64, 560-568, https://doi. org/10.1016/j.carbpol.2005.11.026.

26. Ghani, S. A., Tan, S. J. \& Yeng, T. S. (2013). Properties of chicken feather fiber-filled low-density polyethylene composites: The effect of polyethylene grafted maleic anhydride. Polym. Plast. Technol. Eng., 52, 495-500.

27. Mano, V., Felisberti, M. I. \& de Paoli, M. A. (1997). Influence of $\mathrm{FeCl}_{3}$ on the mechanical, thermal, and dynamic mechanical behavior of PVC. Macromol., 30, 3026-3030, https://doi.org/10.1021/ma961298+. 
28. Li, S. et al. (2010). Unique properties of polyaniline in the presence of applied magnetic field and ferric chloride. Mater. Chem. Phys., 124, 168172, https://doi.org/10.1016/j.matchemphys.2010.06.012.

29. Zhang, Z. et al. (2007). Chemical one step method to prepare polyaniline nanofibers with electromagnetic function. Macromol. Rapid Comm., 28, 585-590, https://doi.org/10.1002/marc.200600729.

30. Zhu, Y. et al. (2009). 3D hollow microspheres assembled from 1D polyaniline nanowires through a cooperation reaction. Macromol. Chem. Phys., 210, 2046-2051, https://doi.org/10.1002/macp.200900317. 